\title{
Pulmonary endothelium-derived PD-L1 induced by the H9N2 avian influenza virus inhibits the immune response of T cells
}

\author{
Qian Zhang ${ }^{1}$, Xiang $\mathrm{Mu}^{2}$, Hong Dong ${ }^{2}, \mathrm{Ge} \mathrm{Hu}^{2}$, Tao Zhang ${ }^{2}$, Cheng He ${ }^{1 *}$ and Naila Siddique ${ }^{3}$
}

\begin{abstract}
Background: The PD-1/PD-L1 pathway is an inhibitory signaling pathway that maintains the balance between the immune response and immunotolerance, and its overactivation in cancer and viral infections inhibits $T$ cell function. The target cells of various viruses, microvascular endothelial cells (MECs) have been shown to be key regulatory points in immune regulation and virion diffusion in vivo during infection with multiple influenza virus subtypes. Furthermore, avian influenza virus (AIV) infection can induce immunosuppression by causing imbalances in immune responses and immune organ damage. Thus, the aim of this study was to investigate whether the H9N2 virus inhibited the immune function of T cells that migrated across MECs by upregulating PD-L1 expression on MECs.

Methods: The susceptibility of rat pulmonary microvascular endothelial cells (RPMECs) to the H9N2 virus was evaluated by a plaque-forming assay and immunofluorescence staining. Then, we quantified the mRNA and protein levels of PD-L1 in RPMECs induced by H9N2 virus infection using quantitative real-time PCR and flow cytometry. The interaction between the activated T cells and RPMECs infected with the H9N2 virus was revealed using a coculture system. The effect of endothelial-derived PD-L1 on T cell function was investigated by using ELISA and flow cytometry with or without a PD-L1-specific antibody.

Results: Surface staining and the plaque-forming assay showed that the H9N2 virus infected and replicated in RPMECs. Both the PD-L1 mRNA level and PD-L1 protein level were upregulated in RPMECs infected with the H9N2 virus. H9N2 virus-induced PD-L1 expression significantly reduced the secretions of IL-2, IFN- $\gamma$ and granzyme B and perforin expression in T cells. The above data were significantly increased after treatment with an anti-PD-L1 antibody, confirming the above mentioned findings. In addition, the induction of PD-L1 expression decreased the proliferative capacity of the cocultured T cells but did not affect the apoptosis rate of T cells.
\end{abstract}

Conclusions: Taken together, the results suggest that the H9N2 virus is able to inhibit the T cell immune response by upregulating PD-L1 expression in pulmonary microvascular endothelial cells.

Keywords: PD-L1, H9N2 virus, Primary microvascular endothelial cells, T cell immune response

\footnotetext{
* Correspondence: chenghe@cau.edu.cn

'Department of Preventive Veterinary Medicine, College of Veterinary

Medicine, China Agricultural University, Beijing 100193, People's Republic of

China

Full list of author information is available at the end of the article
}

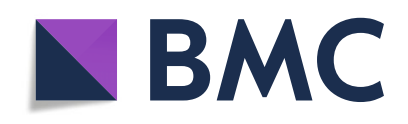

( ) The Author(s). 2020 Open Access This article is licensed under a Creative Commons Attribution 4.0 International License, which permits use, sharing, adaptation, distribution and reproduction in any medium or format, as long as you give appropriate credit to the original author(s) and the source, provide a link to the Creative Commons licence, and indicate if changes were made. The images or other third party material in this article are included in the article's Creative Commons licence, unless indicated otherwise in a credit line to the material. If material is not included in the article's Creative Commons licence and your intended use is not permitted by statutory regulation or exceeds the permitted use, you will need to obtain permission directly from the copyright holder. To view a copy of this licence, visit http://creativecommons.org/licenses/by/4.0/. The Creative Commons Public Domain Dedication waiver (http://creativecommons.org/publicdomain/zero/1.0/) applies to the data made available in this article, unless otherwise stated in a credit line to the data. 


\section{Background}

The avian influenza virus (AIV) H9N2 subtype is one of the major pathogens that affect poultry and was first discovered in the United States in 1966. Recent studies have shown that in addition to infecting fowl, the H9N2 virus also infects mammals such as humans and pigs, indicating cross-species transmission $[1,2]$. Furthermore, the H5N6, H7N9 and H10N8 subtypes, which have evolved from the H9N2 virus through mutations in 6 different genes, cause severe respiratory symptoms in humans [3]. Due to the mild respiratory symptoms of $\mathrm{H} 9 \mathrm{~N} 2$ virus infection, adequate preventive measures have not been taken to control the spread of the virus, thereby allowing it to evolve $[4,5]$. The H9N2 virus often causes secondary infection with other pathogens, due to the downregulation of the host immune response, resulting in respiratory symptoms, aggravation of vaccine failure and even death.

Programmed death ligand 1 (PD-L1), also known as B7$\mathrm{H} 1$ or CD274, is expressed on the activated T cells, B cells, macrophages, tumor cells, interstitial cells, and vascular endothelial cells (ECs), PD-L1 regulates inflammation in the heart, liver, placenta, cornea, retina, and etc. [6, 7]. The abnormal activation and expression of the PD-L1/ PD-1 axis plays an important role in tumor development, chronic infection, and autoimmune diseases [8]. The binding of PD-L1 to its receptor PD-1 promotes the immune escape of viruses by suppressing the immune function of $\mathrm{T}$ cells [9-11]. The PD-1/PD-L1 pathway blocks hepatitis $\mathrm{B}$ virus (HBV)-specific CD8+ T cells by targeting IL-2mediated STAT-5 phosphorylation, which accelerates hepatitis B progression [12]. Similarly, retroviruses inhibit CD8+ T cell expansion and cytotoxicity by inducing PDL1 overexpression [13], while respiratory syncytial virus (RSV) induces PD-L1 in bronchial ECs, which reduces the secretion of cytotoxic molecules by effector CD8+ T cells and ensures the survival of the virus in infected cells [14]. ECs are a target of multiple viruses and trigger both innate and specific immune responses by expressing specific receptors $[15,16]$. Studies have shown that ECs are the key regulators of the immune response and virion diffusion during infection with multiple subtypes of the influenza virus $[16,17]$. However, it is still unclear whether ECs infected by the H9N2 virus affect the T cell immune response, especially in terms of the production of antiviral and cytotoxic proteins. The aims of this study were to investigate whether the H9N2 virus infected primary pulmonary microvascular ECs (PMECs) and whether it could induce PD-L1 expression in PMECs, thereby affecting the immune function of $\mathrm{T}$ cells.

\section{Methods}

\section{Experimental protocol}

We first investigated whether the H9N2 virus infected and replicated in RPMECs using immunofluorescence staining and a plaque-forming assay. Then, we quantified PD-L1 expression in RPMECs induced by H9N2 virus infection using RT-PCR and flow cytometry. Then, the effect of the induction of PD-L1 expression on the function of $\mathrm{T}$ cells was observed by using a coculture system established in transwell chambers with 6-well inserts. Finally, we investigated the levels of TNF- $\alpha$ and IFN- $\gamma$ in the culture supernatants of RPMECs infected with the H9N2 virus.

\section{Isolation of RPMECs and T cells}

RPMECs were isolated from the lungs as previously described with some modifications [18]. Briefly, the excised lung tissues from seven-day-old specific pathogen-free (SPF) F344 rats were rolled on dry filter paper to remove the mucosal layer, washed with phosphate buffered saline (PBS), and minced in fetal bovine serum (FBS, Gibco, Carlsbad, CA, USA). The tissue mass was then seeded in a culture plate, and the excess serum was discarded. The cells that migrated from the tissue blocks were digested with trypsin, washed with PBS, and incubated with a FITC-conjugated anti-CD31 antibody (Abcam, Cambridge, UK). RPMECs were purified by flow cytometry and cultured in EC basal medium (EBM; Lonza, Basel, Switzerland) supplemented with 20\% FBS (Gibco, Carlsbad, CA, USA) and $10 \mathrm{ng} / \mathrm{mL}$ VEGF165 (PeproTech, NJ, USA). The purity of the endothelial cells was verified by staining for vascular endothelial growth factor receptor 2 (VEGFr2) under observation of a laser scanning confocal microscope (Leica TCS SP5, Leica Microsystems, Wetzlar, Germany). In brief, the cells were seeded on the bottom of a glass dish and fixed with methanol-acetone (1:1) for $20 \mathrm{~min}$ at room temperature. After being rinsed with PBS, the cells were incubated with a polyclonal rabbit antibody against rat VEGFr2 (Abcam, Shanghai, China) at $37^{\circ} \mathrm{C}$ for $45 \mathrm{~min}$, washed three times with PBS. and incubated with a FITC-labeled goat anti-rabbit secondary antibody (Origene, Rockville, MD, USA) at $37^{\circ} \mathrm{C}$ for $30 \mathrm{~min}$. The cell nuclei were counterstained with DAPI (4,6-diamidino-2phenylindole dihydrochloride; Cell Signaling Technology, Danvers, MA, USA).

To isolate rat $\mathrm{T}$ cells, blood was collected from F344 rats, and peripheral blood mononuclear cells (PBMCs) were isolated by polysucrose and sodium diatrizoate density gradient separation (Sigma Aldrich, Shanghai, China) as previously described [19]. The PBMCs were incubated in RPMI 1640 medium containing 10\% FBS at $37{ }^{\circ} \mathrm{C}$ under $5 \% \mathrm{CO}_{2}$ for $2 \mathrm{~h}$ to facilitate monocyte adhesion. Negative selection enrichment columns (R\&D Systems, MN, USA) were then used to enrich $T$ cells according to the manufacturer's protocol. The isolated $\mathrm{T}$ cells were cultured in RPMI 1640 medium (Gibco, Carlsbad, CA, USA) supplemented with $10 \%$ FBS for $72 \mathrm{~h}$, 
and cells isolated from the unvaccinated rats were cultured in the same medium containing $5 \mu \mathrm{g} / \mathrm{mL}$ CD3 (Santa Cruz Biotechnology, Dallas, USA), $5 \mu \mathrm{g} / \mathrm{mL}$ CD28 (Abcam, Cambridge, UK) and $10 \mu \mathrm{g} / \mathrm{ml}$ PHA (Sigma Aldrich, Shanghai, China) for $72 \mathrm{~h}$. To activate the isolated $\mathrm{T}$ cells, F344 rats were infected with $100 \mu \mathrm{L}$ virus solution $\left(2 \times 10^{7}\right.$ plaque-forming units, PFUs) by nasal drip, and then $\mathrm{T}$ cells were isolated on the 7 th day postinfection.

\section{In vitro virus infection}

The $\mathrm{H} 9 \mathrm{~N} 2$ virus $(\mathrm{Ck} / \mathrm{HB} / 4 / 08)$ was inoculated into 9day-old SPF chicken embryos, and virus titers were determined by measuring PFUs. Madin-Darby canine kidney (MDCK, CCL-34, ATCC) cells used for PFUs were cultured in DMEM media supplemented with 5\% FBS. AIV-specific sialic acid $\alpha$-2,3-galactose receptor (SA23Gal) expression was confirmed by biotinylated Maackia amurensis lectin II (VECTOR, CA, USA) staining and then followed by staining with FITC-conjugated avidin D (green) and DAPI (blue) for nuclei. To assess H9N2 virus infection, RPMECs were washed with PBS, inoculated with virus at different multiplicities of infection (MOIs) and incubated for $1 \mathrm{~h}$. Then, the cells were washed with PBS and incubated with DMEM, $0.2 \%$ bovine serum albumin (Gibco, Carlsbad, CA, USA) and $0.2 \mu \mathrm{g} / \mathrm{mL}$ TPCK-treated trypsin [20]. Viral titers in the supernatants were measured using PFUs. To investigate the PD-L1 level induced by inactivated H9N2 virus, viral particles were inactivated using $0.094 \% \quad \beta$ propionolactone (BPL; SERVA Electrophoresis, Heidelberg, Germany) according to a previously described protocol [21].

\section{RPMEC/T cell coculture system}

The $\mathrm{T}$ cell/RPMEC coculture system was established in transwell chambers with 6-well inserts (Corning, Shanghai, China). The RPMECs were seeded in the upper chambers at a concentration of $1 \times 10^{5}$ cells/well, and the confluence of the RPMEC monolayers was detected on days $0,1,2$ and 3 by measuring permeability to FITClabeled dextran (Sigma Aldrich, Shanghai, China). Then, RPMECs were infected with the H9N2 virus or inoculated with viral particles. After $24 \mathrm{~h}$, T cells were plated over the infected monolayer and incubated for $8 \mathrm{~h}$, Afterwards, the migrated $\mathrm{T}$ cells in the lower chamber were harvested and analyzed further. A viral particle control was used since normal MECs expressed very low levels of adhesion molecules, which caused a decreased proportion of migrating $\mathrm{T}$ cells. The transmigrated $\mathrm{T}$ cells in samples from the bottom chamber were counted by a TC-20 cell counter (BioRad, CA, USA).

\section{RT-PCR}

RPMECs infected with live H9N2 virus or inoculated with viral particles were harvested at 6,12 and $24 \mathrm{~h}$ postinfection, and total RNA was isolated using TRIzol reagent (Invitrogen, Carlsbad, CA, USA). The fold change of the PD-L1 mRNA level in different groups relative to the control group was calculated using GAPDH as the housekeeping gene. The primer sequences were as follows: GAPDH: F, 5' ACAACTTTGGTATCGTGGAA GGAC3' and R, 5'AGGGATGATGTTCTGGAGAG CC3'; PD-L1: F, 5'GGAGGACCTGAAGCCTCAAC3' and R, 5'CGTCCTGCAGCTTGACATCT3'.

\section{Flow cytometry}

The RPMECs were harvested, and a single cell suspension was obtained [22]. Then, the cells were incubated with a PE-labeled antibody against PD-L1 (BioLegend, CA, USA) and a FITC-labeled antibody against H9N2 virus hemagglutinin (Sino Biological, Beijing, China). To detect intracellular perforin, the $\mathrm{T}$ cells were fixed, permeabilized with 4\% paraformaldehyde in PBS for $10 \mathrm{~min}$ at room temperature and stained with an anti-perforin primary antibody (Santa Cruz Biotechnology, Dallas, USA) and a FITC-labeled secondary antibody (ORIGENE, Rockville, MD, USA). All labeled cells were analyzed by flow cytometry, and 10,000 events were acquired per sample. The protein expression levels were evaluated in terms of the percentage of positively labeled cells.

\section{MTT assay}

To determine the proliferation rate of the migrated $\mathrm{T}$ cells, $\mathrm{T}$ cells harvested from the coculture system were resuspended in medium and seeded in 96-well plates at a density of $1 \times 10^{4}$ cells/well. After adding PHA to a final concentration of $5 \mu \mathrm{g} / \mathrm{mL}$, the cells were cultured for 24,48 or $72 \mathrm{~h}$. Then $10 \mu \mathrm{L}$ 3-(4, 5-Dimethyl-2-Thiazolyl)-2, 5-Diphenyl-2$\mathrm{H}$-Tetrazolium Bromide (MTT, $5 \mathrm{mg} / \mathrm{mL}$, Sigma, Shanghai, China) solution was added to each well for $4 \mathrm{~h}$, followed by $150 \mu \mathrm{L}$ DMSO (Sigma, Shanghai, China). Finally, the optical density at $490 \mathrm{~nm}$ was measured at each time point.

\section{Annexin V-FITC and propidium iodide staining}

To detect the apoptosis rate of the migrated $\mathrm{T}$ cells, cells were stained with Annexin V-FITC and PI for $20 \mathrm{~min}$ according to the manufacturer's protocol (Santa Cruz Biotechnology, Dallas, USA). The percentage of apoptotic cells was measured by flow cytometry.

\section{ELISA assay}

To evaluate the levels of IL-2, IFN- $\gamma$ and granzyme B, T cells that migrated to the lower chamber were harvested, reseeded in a 12-well plate, and cultured for $48 \mathrm{~h}$. The supernatants were collected and measured by ELISA kits (R\&D Systems Inc., MN, USA) according to the 
manufacturer's instructions. To determine the levels of IFN- $\gamma$ and TNF- $\alpha$ induced by the H9N2 virus, T cells were infected with the H9N2 virus at an MOI of 1 or 5 . Supernatants were collected from each group at $12 \mathrm{~h}$ and $24 \mathrm{~h}$ postinfection and analyzed using ELISA kits (R\&D Systems Inc., USA).

\section{PD-L1 CRISPR activation plasmid transfection}

For the overexpression assay, RPMECs seeded in upper chambers at a concentration of $1 \times 10^{5}$ cells/well were transfected with the control plasmid or PD-L1 CRISPR activation plasmid (the details of the plasmids were provided in the supplementary material) using a Lipofectamine 3000 transfection reagent kit (Invitrogen, Carlsbad, CA, USA). According to the kit instructions, mixtures of plasmid $(2 \mu \mathrm{g})$ and Lipofectamine 3000 transfection reagent $(7.5 \mu \mathrm{L})$ using Opti-MEM were prepared. Then, the mixture was added to the RPMECs for $72 \mathrm{~h}$ at $37^{\circ} \mathrm{C}$ in a $5 \% \mathrm{CO}_{2}$ incubator. The overexpression level of PDL1 was detected at $72 \mathrm{~h}$ after transfection by western blotting, and the ratio of PD-L1 to $\beta$-actin was determined by ImageJ software (NIH, USA).

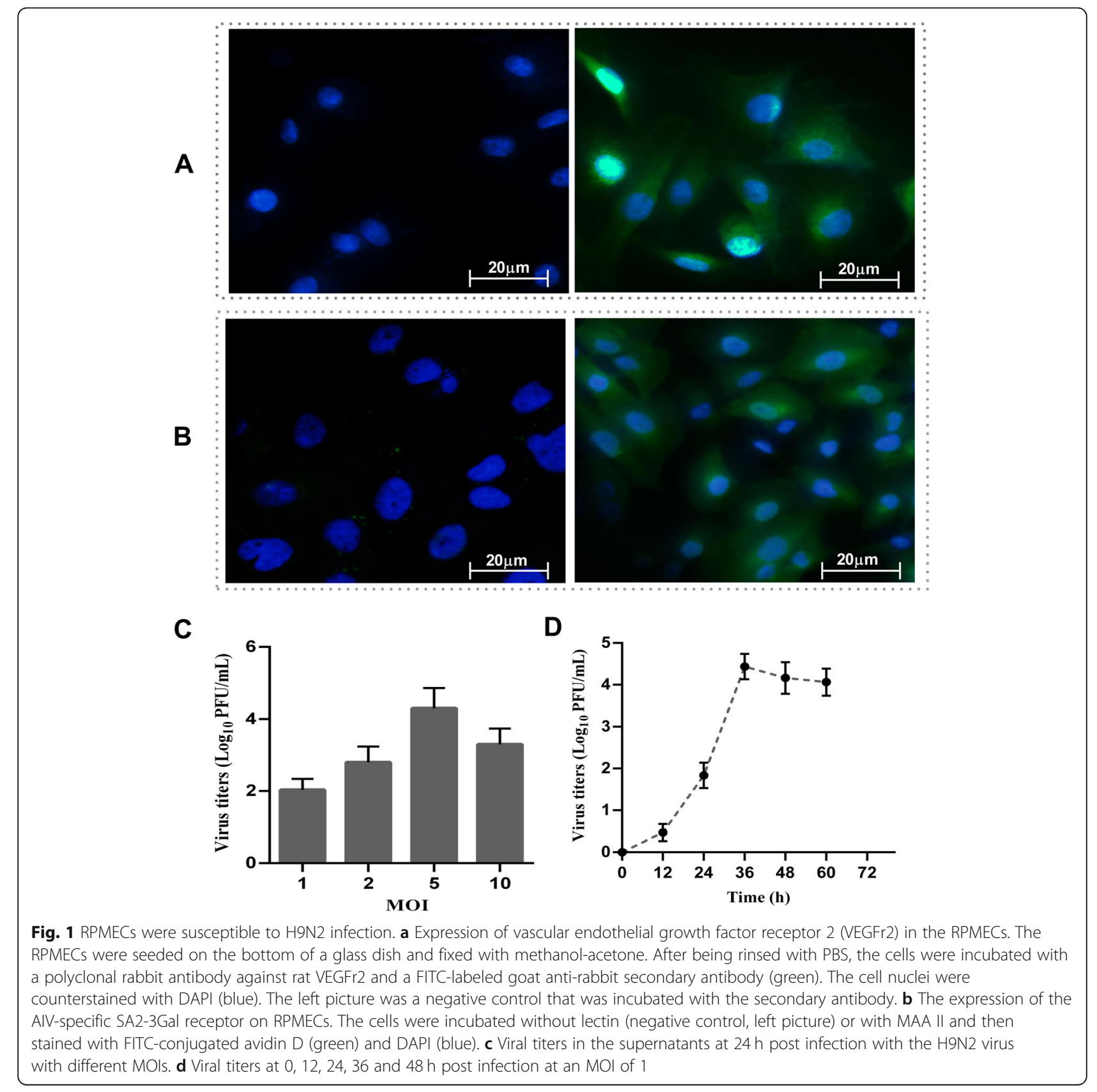



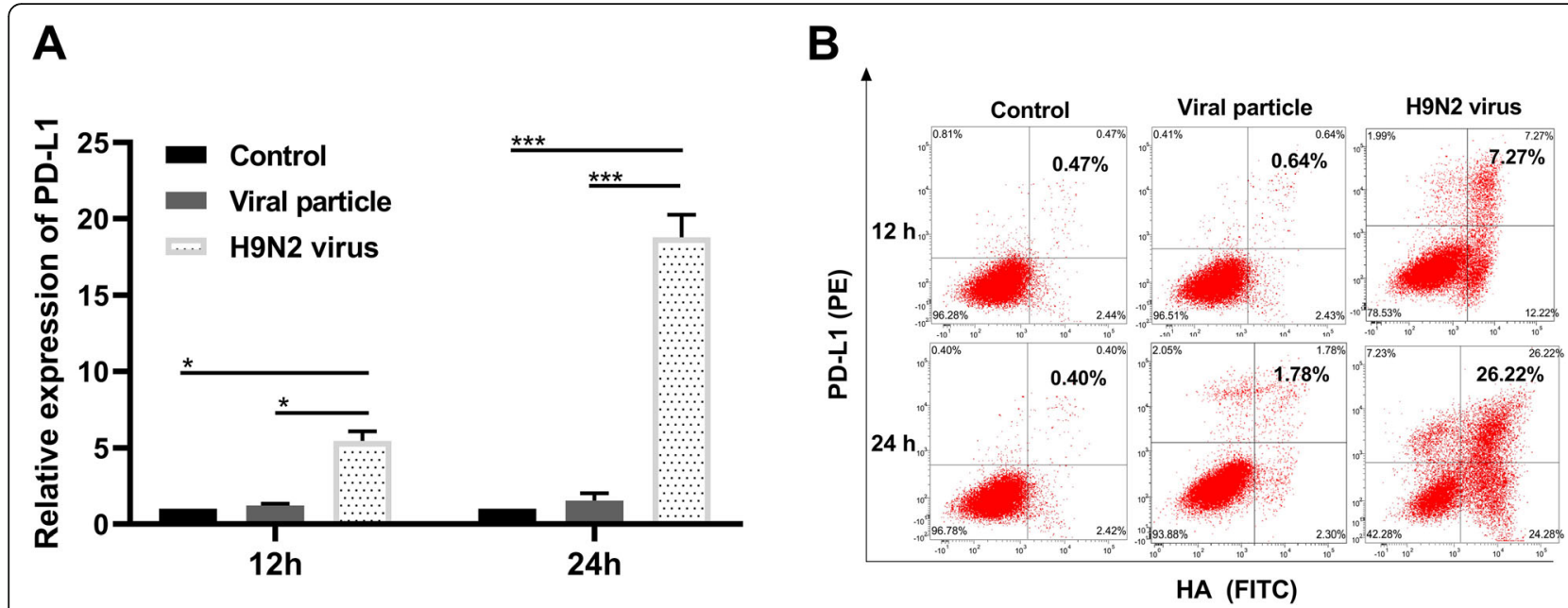

Fig. 2 PD-L1 expression in the RPMECs infected with the live H9N2 virus or with the inactivated viral particles. PD-L1 mRNA and protein levels in the RPMECs were detected at 12 and $24 \mathrm{~h}$ post infection with the H9N2 virus (H9N2 virus) or with the inactivated H9N2 viral particles at an MOI of 5 (Viral particle). a PD-L1 mRNA levels post infection with the live H9N2 or with the inactivated H9N2 viral particles. b PD-L1 protein levels post infection with the live H9N2 or with the inactivated H9N2 viral particles. * Statistical analysis among the live H9N2 group, the inactivated H9N2 viral particle group and the control group at $12 \mathrm{~h}$ and $24 \mathrm{~h}\left({ }^{*} P<0.05,{ }^{* *} P<0.001\right)$

\section{Statistical analysis}

The data were analyzed using GraphPad Prism software 6.0 (GraphPad, La Jolla, CA, USA). The results were expressed as the mean \pm standard deviation (SD) of at least 3 independent experiments. The different groups were compared using Student's t-test or one-way analysis of variance (ANOVA) as appropriate. A $p$-value < 0.05 was considered statistically significant.

\section{Results}

H9N2 virus infects and proliferates in RPMECs

As shown in Fig. 1 a, the expression of positive vascular endothelial growth factor receptor 2 was found in the MECs. Since AIVs preferentially bind to SA2-3Gal, we also analyzed the surface pattern of SA2-3Gal expression on RPMECs and found that the specific receptor for the H9N2 virus was expressed in the RPMECs (Fig. 1b). The plaque-forming assay showed that infection at MOIs of $1,2,5$ and 10 produced $2.03 \times 10^{4}$, $2.8 \times 10^{4}, 4.3 \times 10^{4}$ and $3.3 \times 10^{4} \mathrm{PFUs} / \mathrm{ml}$, respectively, in the RPMECs after $24 \mathrm{~h}$ (Fig. 1c). Subsequently, we tested infection at an MOI of 1 for different incubation times and found that viral titers peaked at $36 \mathrm{~h}$ (Fig. 1d). Taken together, these results suggest that RPMECs facilitate H9N2 virus proliferation in the presence of exogenous trypsin.

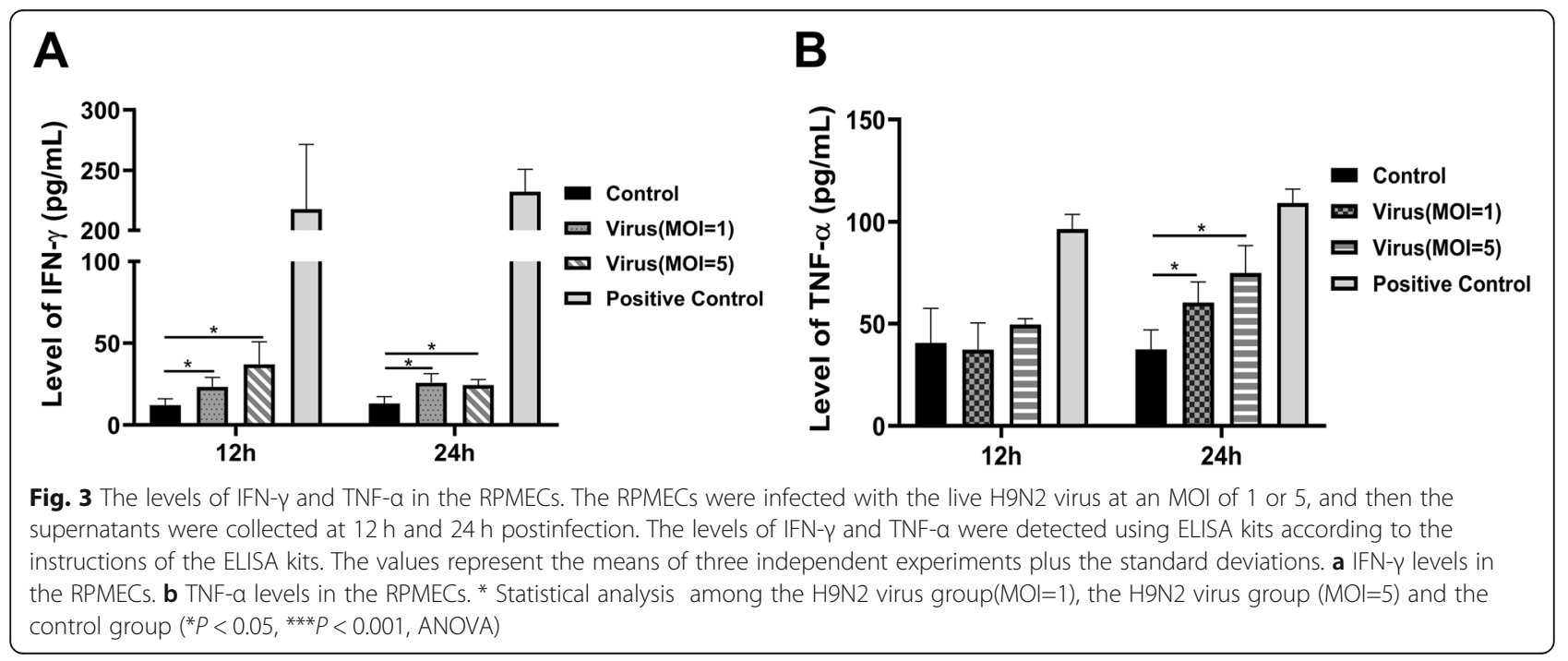



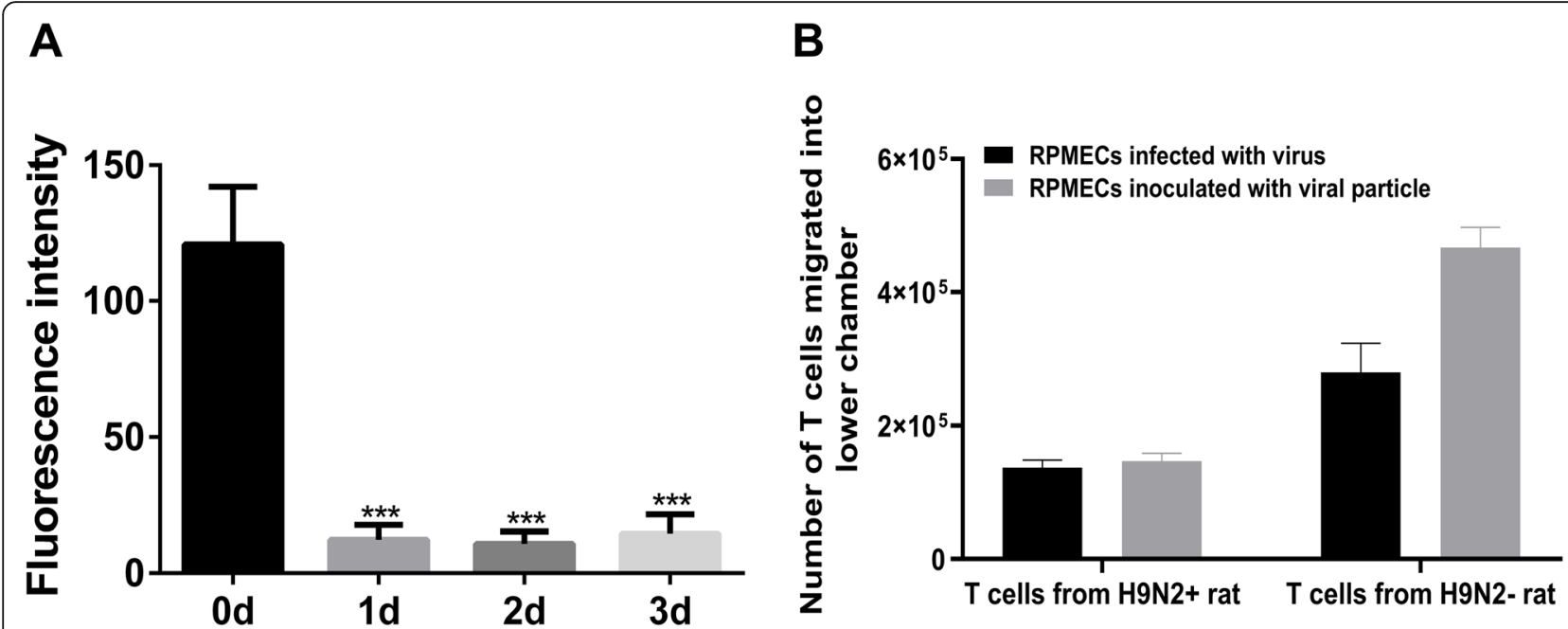

Fig. 4 Determination of transmigrated T cells. RPMECs were cultured on transwell filters, and confluence was assessed by measuring the fluorescence intensity in the lower chamber. T cells $\left(1 \times 10^{6}\right.$ cells per well) were added to the top chamber and allowed to transmigrate for $8 \mathrm{~h}$. Then, the transmigrated T cells were counted by detecting fluorescence intensity. $\mathbf{a}$ The confluence of RPMECs on days $0,1,2$ and 3. $\mathbf{b}$ The numbers of transmigrated T cells. T cells from H9N2+rat indicated that T cells were isolated from H9N2 virus-infected rats. T cells from H9N2-rat indicated that T cells were isolated from rats with the inactivated H9N2 viral particles. * Statistical analysis of RPMECs confluence at different time points $\left({ }^{* * *} P<0.001\right.$, t-test)

H9N2 infection upregulates PD-L1 expression in RPMECs PD-L1 mRNA and protein levels in the differentially treated RPMECs were detected by RT-PCR and flow cytometry. The results showed that the inactivated viral particle did not induce the expression of PD-L1. In contrast, live H9N2 virus significantly induced the expression of PD-L1 at the mRNA and protein levels in RPMECs in a time-dependent manner (Fig. $2 \mathrm{a}, \mathrm{b}, \mathrm{P}<0.05)$. The higher levels of PD-L1 at $24 \mathrm{~h}$ compared to $12 \mathrm{~h}$ postinfection were likely due to virus replication in RPMECs. Taken together, these results suggest that $\mathrm{H} 9 \mathrm{~N} 2$ virus infection significantly increases PD-L1 expression in the RPMECs.

\section{IFN- $\gamma$ and TNF- $\alpha$ levels in the RPMECs infected with the} H9N2 virus

As described previously, IFN- $\gamma$ can rapidly induce PD-L1 expression [23], and TNF- $\alpha$ can enhance the ability of IFN- $\gamma$ to induce PD-L1 expression [24]. Therefore, we investigated whether IFN- $\gamma$ and TNF- $\alpha$ were induced in the H9N2 virus-infected RPMECs. The results showed that $\mathrm{H} 9 \mathrm{~N} 2$ virus infection significantly increased the levels of IFN- $\gamma$ in the RPMECs at 12 and $24 \mathrm{~h}$ (Fig. $3 \mathrm{a}, P<0.05$ ). However, the levels of TNF- $\alpha$ were only elevated at $24 \mathrm{~h}$ (Fig. 3b, $\mathrm{P}<0.05$ ). This result may explain why the level of PD-L1 at $24 \mathrm{~h}$ was higher than that at $12 \mathrm{~h}$.

\section{H9N2 virus-induced PD-L1 inhibits the immune response of $\mathrm{T}$ cells in vitro and in vivo}

A transwell coculture system was used to investigate the role of $\mathrm{H} 9 \mathrm{~N} 2$ virus-induced PD-L1 expression in the interaction between RPMECs and $\mathrm{T}$ cells. In this experiment, we first investigated the migration rate of $\mathrm{T}$ cells across a RPMEC monolayer infected with the live H9N2 virus or inoculated with viral particles. As shown in Fig. 4a, RPMECs cultured on the transwell filter were completely fused; thus, the $\mathrm{T}$ cells could not pass through the pores of the transwell filter. The migration of $\mathrm{T}$ cells across the RPMEC monolayer was observed (Fig. 4b). The levels of IL-2, IFN- $\gamma$, granzyme B and perforin induced by $\mathrm{T}$ cells that migrated across RPMECs were evaluated by using ELISA kits and flow cytometry. The results showed that the levels of IL-2 (Fig. 5a, $P<0.05$ ), IFN- $\gamma$ (Fig. 5b, $P<0.05$ ) and granzyme $\mathrm{B}$ (Fig. $5 \mathrm{c}, P<0.05$ ) secreted by $\mathrm{T}$ cells that migrated across RPMECs infected with the $\mathrm{H} 9 \mathrm{~N} 2$ virus were significantly decreased. In addition, the proportion of perforin $+\mathrm{T}$ cells was also significantly reduced following migration across RPMECs infected with the H9N2 virus (Fig. $5 \mathrm{~d}, P<0.05$, t-test). However, the levels of these factors expressed by $\mathrm{T}$ cells that migrated across RPMECs infected with the H9N2 virus were restored when we blocked PD-L1 with a specific antibody (Fig. 5a, b, and c).

To investigate the effect of PD-L1 on the immune response of $\mathrm{T}$ cells from H9N2 virus-infected rats, we cocultured the $\mathrm{T}$ cells with RPMECs infected with the live H9N2 virus or with the viral particles. The results showed that $\mathrm{T}$ cells that migrated across virus-infected RPMECs expressed lower levels of IL-2 (Fig. 6a, $P<0.05$ ), IFN- $\gamma$ (Fig. 6b, $P<0.05$ ) and granzyme B (Fig. $6 c, P<0.05$ ) than $\mathrm{T}$ cells that migrated across viral particle-inoculated RPMECs. Similarly, the proportion of perforin $+\mathrm{T}$ cells was also significantly reduced (Fig. $6 \mathrm{~d}, P<0.05$, t-test). In 


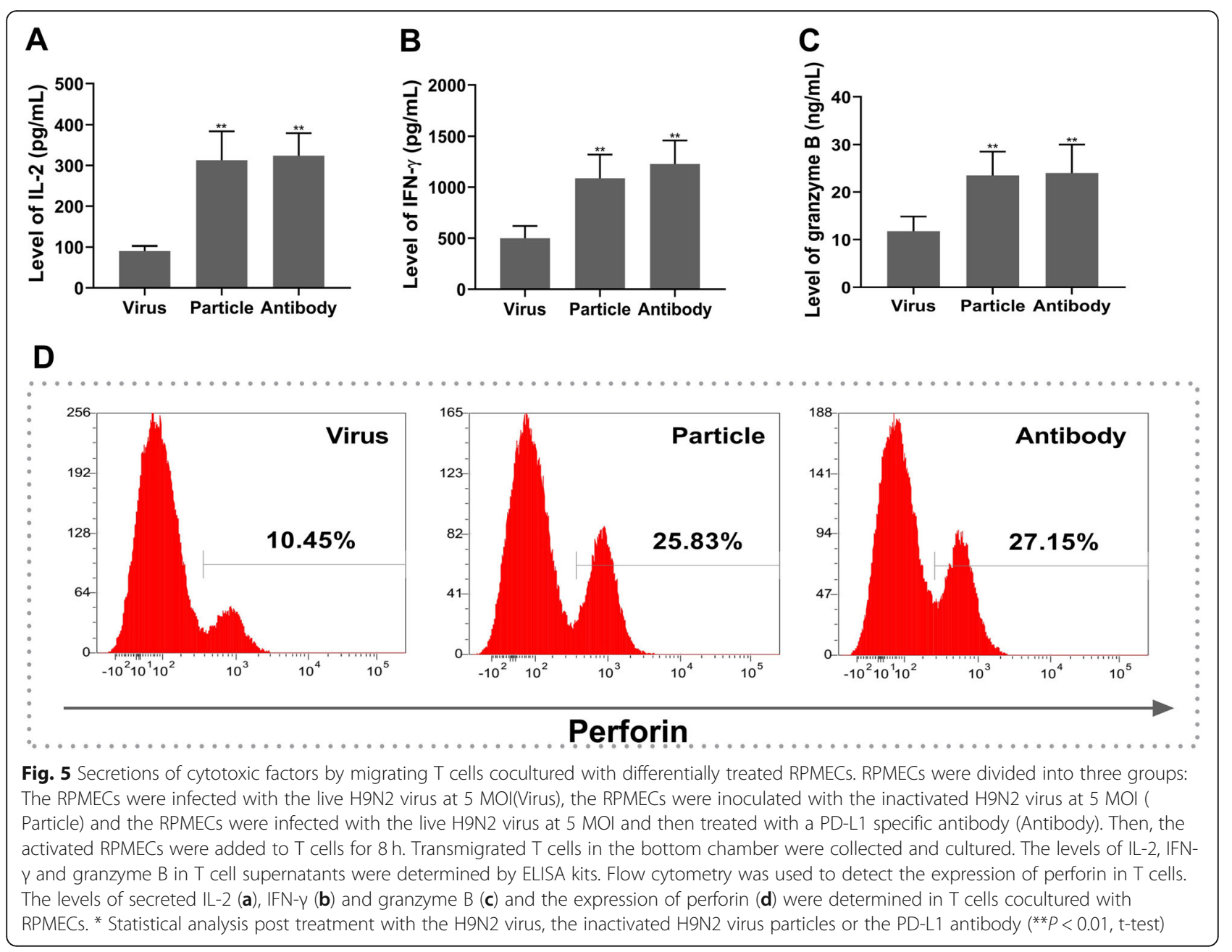

the activated $\mathrm{T}$ cell cocultures, treatment with the antiPD-L1 antibody restored the immune function of the T cells. All the data indicated that PD-L1 expressed on H9N2 virus-infected RPMECs inhibited the immune function of migrated $\mathrm{T}$ cells.

\section{H9N2 virus-induced PD-L1 inhibits the proliferation of T cells without affecting apoptosis}

As shown in Fig. 7a, cocultivation of the activated $\mathrm{T}$ cells with H9N2 virus-infected RPMECs produced a significantly lower proliferation rate than the viral particle group did, and the proliferation rate was restored after PD-L1 was blocked. Similarly, the proliferative capacity of $\mathrm{T}$ cells from H9N2 virus-infected rats was also suppressed after the $\mathrm{T}$ cells migrated across RPMECs infected with the live H9N2 virus and was restored after PD-L1 was blocked (Fig. 7). In addition, the percentages of Annexin V+ apoptotic $\mathrm{T}$ cells were $2.1 \%, 2.0 \%$ and $3.0 \%$, respectively in the live H9N2 virus group, the viral particle group and the PD-L1 antibody group (Fig. 8a). Similar results were obtained for $\mathrm{T}$ cells isolated from
H9N2 virus-infected rats (Fig. 8b). Taken together, these results suggested that the high levels of PD-L1 on RPMECs induced by H9N2 virus infection inhibited the proliferation of migrated $\mathrm{T}$ cells.

\section{PD-L1 overexpression significantly suppresses the immune response of $\mathrm{T}$ cells}

RPMECs were inoculated with viral particles for $48 \mathrm{~h}$ post plasmid transfection. After $24 \mathrm{~h}$, the $\mathrm{T}$ cells were plated over an RPMEC monolayer and incubated for $8 \mathrm{~h}$. Migrated T cells in the lower chamber were harvested and analyzed further. The results showed that transfection with the PD-L1 CRISPR activation plasmid elevated the expression of PD-L1 in the RPMECs (Fig. 9a). Compared to those in the control group, the levels of IL-2 and perforin were significantly decreased (Fig. 9b, and c, $P<0.05$ ).

\section{Discussion}

Currently, the H9N2 virus is widespread in poultry throughout Asia and can also infect mammals [25], including humans [26]. The efficacy of influenza virus 


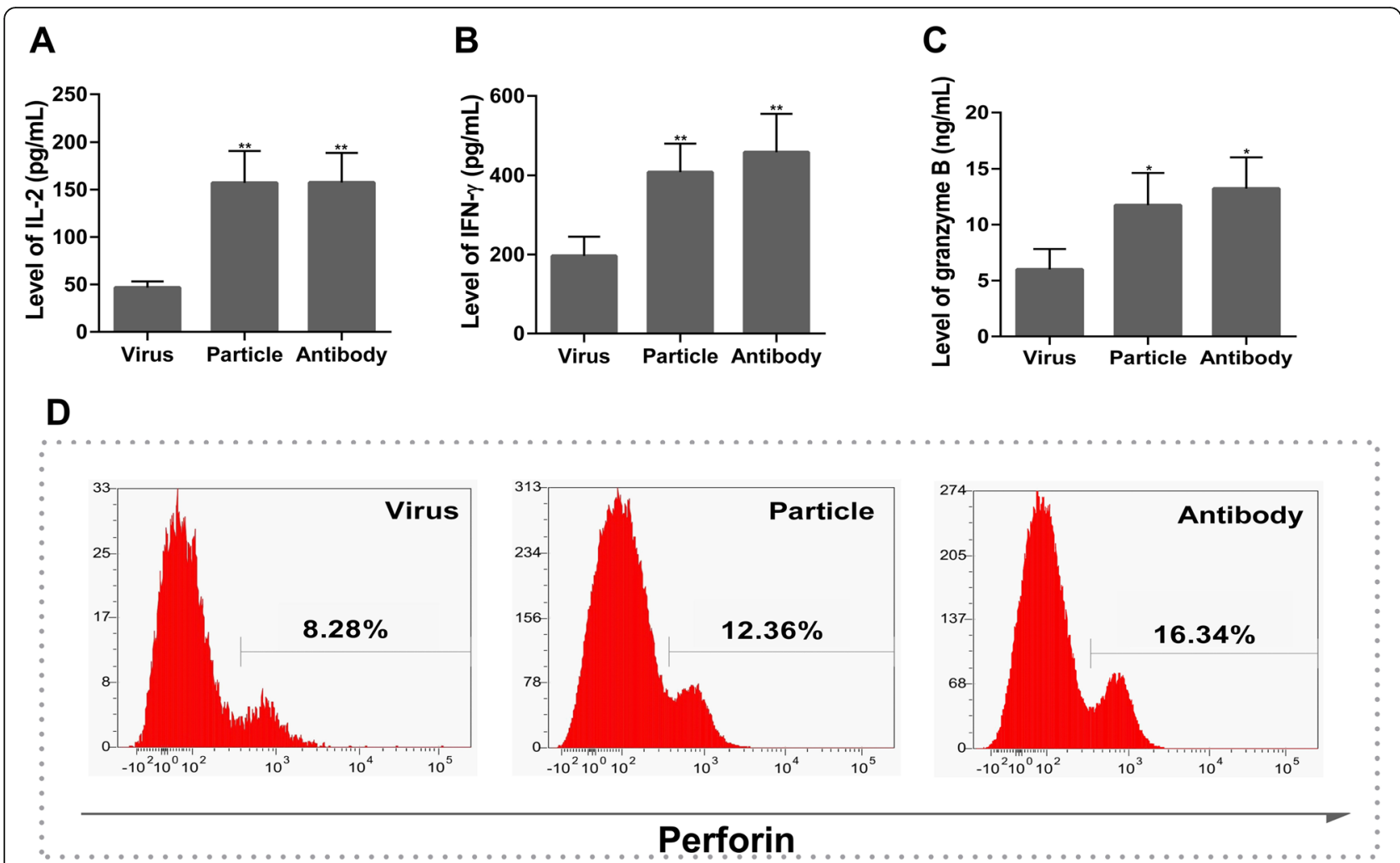

Fig. 6 Secretion of cytotoxic factors by the migrated T cells from H9N2 virus-infected rats. The RPMECs were divided into 3 groups: RPMECs from rats infected with the live H9N2 virus (Virus), RPMECs from rats inoculated with the inactivated H9N2 virus (Particle), RPMECs from rats infected the live H9N2 virus and then treated with a PD-L1-specific antibody (Antibody). Then the activated RPMECs were added to the T for $8 \mathrm{~h}$. The levels of secreted IL-2 (a), IFN- $\mathrm{Y}(\mathrm{B} \mathbf{b})$ and granzyme B (c) by T cells and the expression of perforin (d) post the different RPMECs cocultured with $T$ cells. * indicates the particle or antibody group compared with the virus group. Statistical analysis of cytotoxic factors post treatment with RPMECS from H9N2 virus-infected rats, or RPMECs from the viral particles or the PD-L1 antibody $\left({ }^{*} P<0.05,{ }^{*} P<0.01\right)$
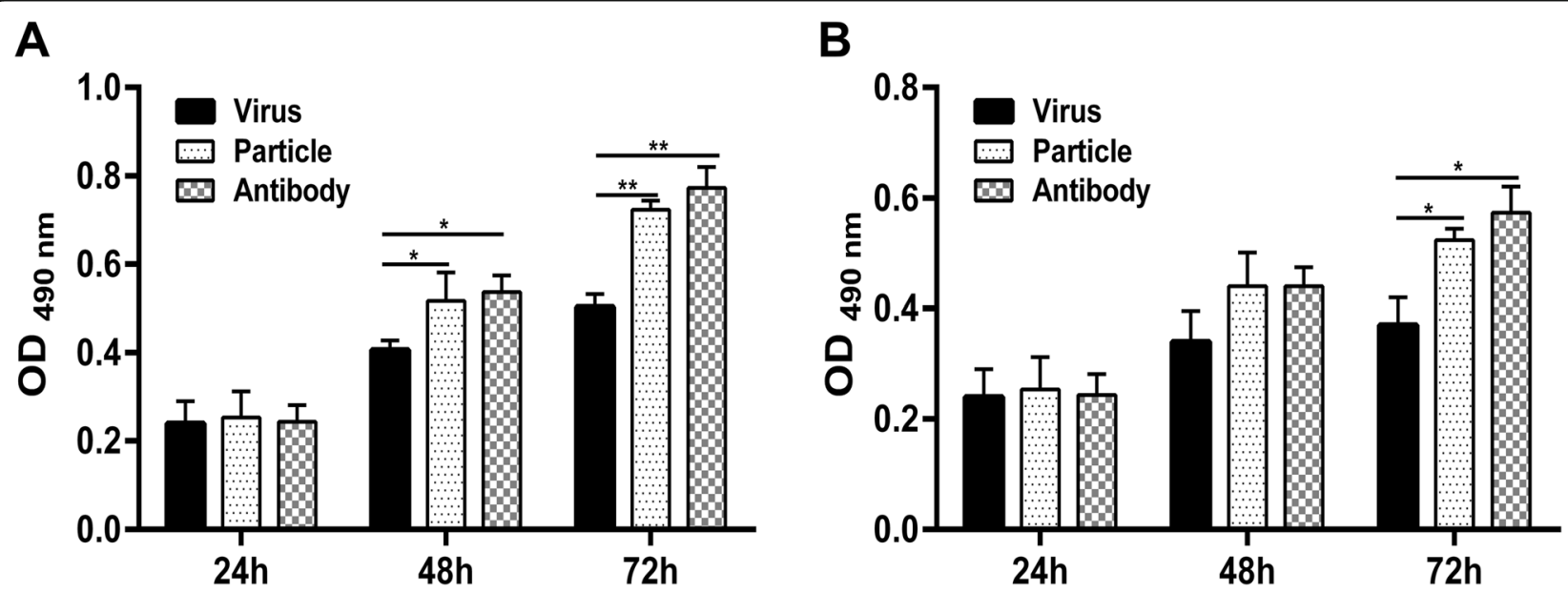

Fig. 7 Effect of H9N2 virus-induced PD-L1 on the proliferation of T cells. RPMECs were treated with the H9N2 virus (Virus), viral particles (Particle) or the H9N2 virus plus a PD-L1 antibody (Antibody), and then the activatedT cells were added to endothelial cells for $8 \mathrm{~h}$ in vitro. Migrated T cells in the bottom chamber were collected for the MTT assay. The MTT results showed the proliferation rate of T cells that migrated across RPMECs. a The proliferation rate of the activated T cells in vitro. $\mathbf{b}$ The proliferation rate of T cells isolated from H9N2 virus-infected rats. * Statistical analysis of T cell proliferation post treated with the H9N2 virus,or the inactivated H9N2 viral particles or the H9N2 virus+ PD-L1 antibody $\left({ }^{*} P<0.05,{ }^{* *} P<0.01\right)$ 


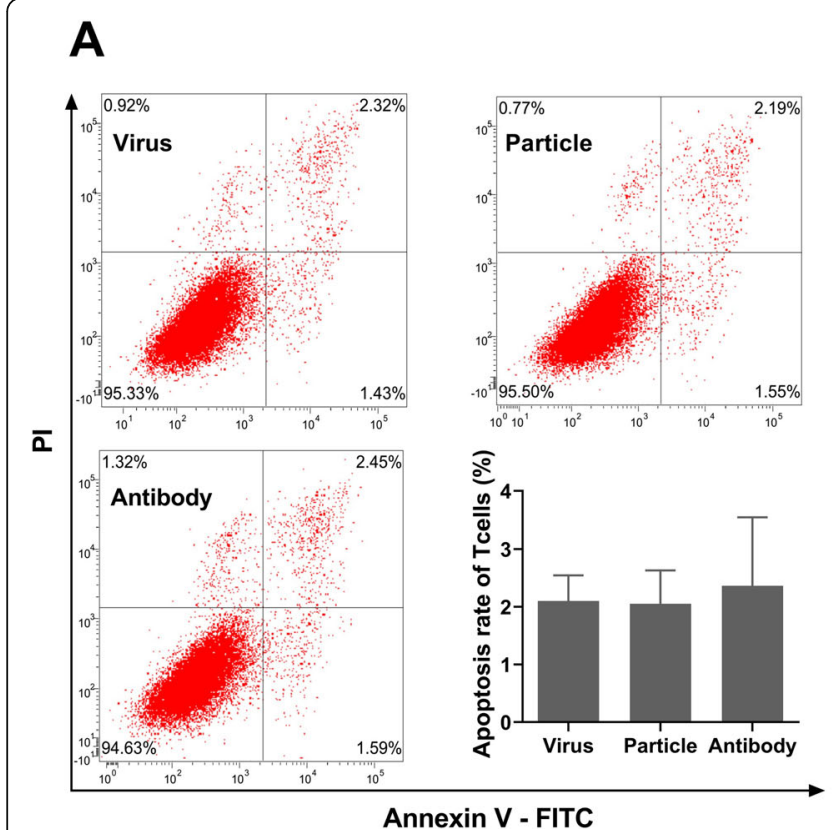

B

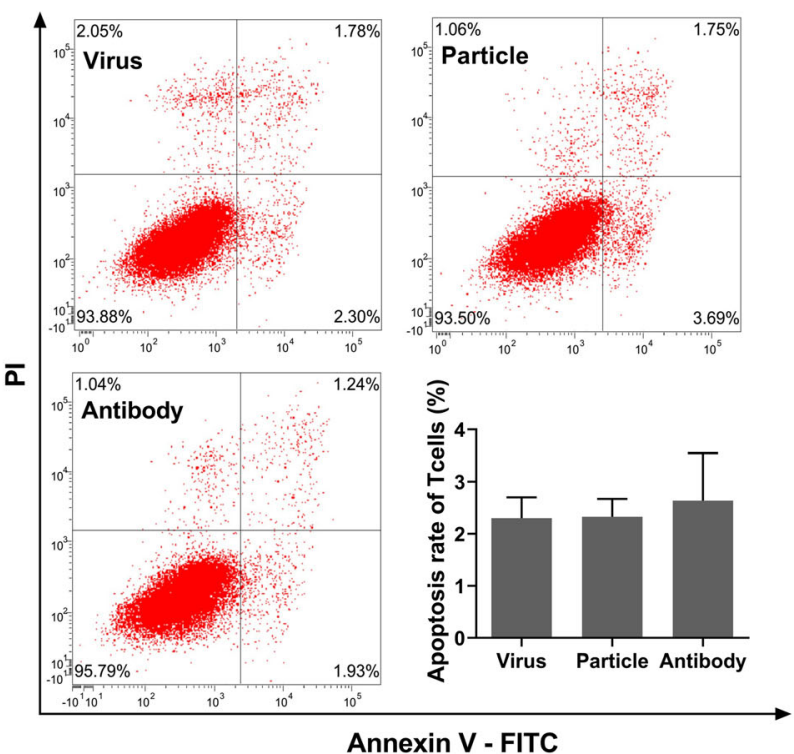

Fig. 8 Effect of H9N2-induced PD-L1 on the apoptosis of T cells. Annexin-V/Pl-stained apoptotic T cells that migrated across RPMECs treated with the H9N2 virus (Virus), viral particles (Particle) or the H9N2 virus plus a PD-L1 antibody (Antibody). a The apoptosis rates of T cells activated in vitro. $\mathbf{b}$ The apoptosis rates of T cells isolated from H9N2 virus-infected rats

infection depends on the presence of specific sialic acid receptors on the cell surface [27]. In general, respiratory epithelial cells are considered to be target cells of influenza viruses [28]. However, increasing evidence has shown that MECs also play an important role in the immune response to influenza virus. Moreover, the previous reports have shown that $\mathrm{H} 5 \mathrm{~N} 1$ and H7N9 subtypes can directly infect human lung MECs and replicate in EC lines [29]. Therefore, to determine the susceptibility of primary RPMECs to the H9N2 virus, we detected SA2-3Gal expression on RPMECs, which indicates that these cells are susceptible to AIV. Subsequent plaque analysis revealed that progeny virus was detected in the culture supernatant of RPMECs inoculated with the H9N2 virus, indicating the intracellular replication of the virus. The results indicate that the H9N2 virus can infect and replicate in primary RPMECs. This result may further explain the multiple organ hemorrhages post infection with $\mathrm{H} 9 \mathrm{~N} 2$ virus.

PD-L1 expression can be induced in many cell types, and increased expression has been observed in tumors and infections. A previous study showed that respiratory syncytial virus (RSV) induces PD-L1 expression on bronchial epithelial cells, which inhibits the antiviral effects of local CD8+ T cells [14], indicating that epithelial cells interact with $\mathrm{T}$ cells during virus infection. ECs play an important role in initiating and modulating peripheral immune responses by interacting with $\mathrm{T}$ cells via CD58, B7-H1, ICOS ligands, OX40 ligands and CD40 [30, 31].
MECs are considered a key regulator of immune responses to multiple influenza virus subtypes [17]. The clinicopathological changes caused by AIV are also closely related to MEC dysfunction [32]. Thus, investigating the interaction between the $\mathrm{H} 9 \mathrm{~N} 2$ virus and RPMECs helps to elucidate the immune response to H9N2 virus infection. In the present study, we demonstrated that the levels of PD-L1 are significantly upregulated in the primary RPMECs infected with the H9N2 virus. Furthermore, our results indicated that virus infection-induced PD-L1 expression transmits a negative signal to migrating $\mathrm{T}$ cells, resulting in the downregulation of antiviral cytokines and a decrease in cytotoxic protein production. In addition, by overexpressing PDL1 in normal RPMECs, we found that elevated PD-L1 also inhibited the function of migrating $T$ cells. Previous studies have shown that hepatitis C, hepatitis B and simian immunodeficiency viruses significantly increase PD-1 expression on effector $T$ cells during the acute phase of infection before the virus becomes persistent or latent. However, the presence of PD- 1 on effector T cells does not induce the depletion of these cells, indicating that the PD-1 ligand level contributes to the extent of PD-1/PD-L1 signaling during infection. Although studies have shown that PD-LI expression is elevated in T cells after viral infection, our previous microarray study indicated that PD-L1 levels were elevated in endothelial cells infected with the H9N2 virus but that the PD-1 ligand levels were not significantly increased. The ligands of 


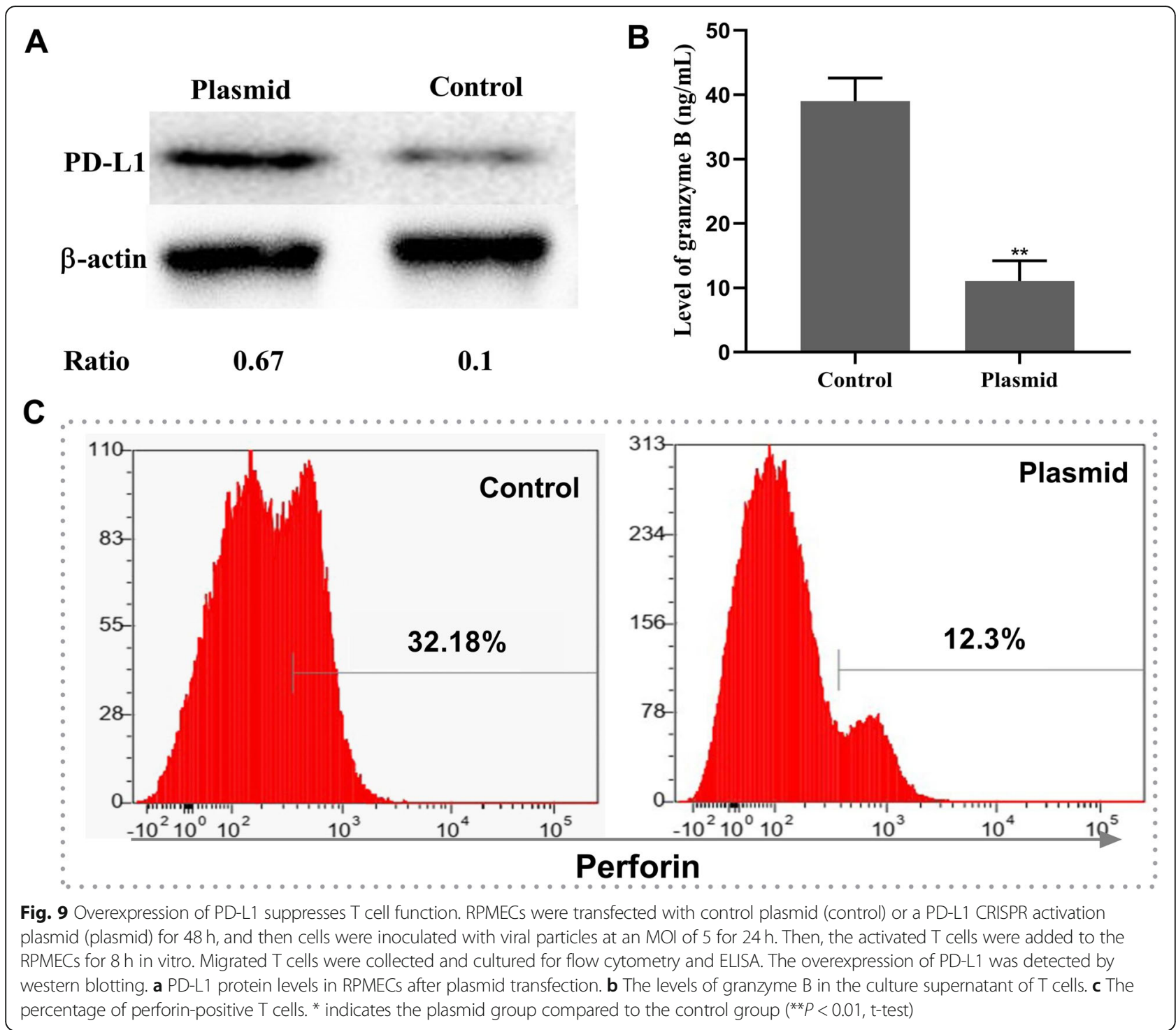

PD-1 and PD-L2 are preferentially expressed on antigenpresenting cells. Therefore, we only explored the regulation of $\mathrm{T}$ cell function by H9N2 virus-induced PD-L1.

AIV infection escapes the host immune response either by inducing an inflammatory reaction or by inhibiting immunity via IFN- $\gamma$ blockade [33], which is the primary cause of vaccine failure in livestock and poultry industry [34]. Although in vivo studies have not clearly elucidated the role of MECs during AIV infection, the lung injury seen in infected hosts indicates EC dysfunction [35]. The alveolar epithelium is separated from MECs by only a $100 \mathrm{~nm}$-thick basal layer, making it easily accessible to viral progeny [36]. Furthermore, since cytokines such as IL-1, IFN- $\gamma$ and TNF- $\alpha$ can induce PD-L1 expression, the inflammatory reaction triggered by influenza viruses may also be a factor in the induction of PD-L1 expression on ECs [37]. Moreover, our study also showed that H9N2 virus infection can increase the levels of IFN- $\gamma$ and TNF- $\alpha$ in the primary RPMECs. In vivo studies have shown that RSV ensures its survival in infected tissue cells by inducing PD-L1 expression on bronchial epithelial cells [38]. Many viruses that cause chronic infections can evade the immune response and attenuate the antiviral $\mathrm{T}$ cell response via the PD-1/PD-L1 inhibitory pathway, resulting in persistent clinical signs of viral infection [39]. Similarly, the induction of PD-L1 expression on RPMECs by the H9N2 virus may be one of the mechanisms of immune escape. H9N2 virus-induced PD-L1 decreased T cell proliferation, which was restored by blocking PDL1, but had no effect on apoptosis. Since rodent ECs 
express only MHC class I receptor [40], the inhibitory effect of PD-L1 on T cell proliferation is likely mediated by cell cycle arrest.

Further studies are necessary to enhance the understanding the pathogenesis provided by our present results. The exact mechanism still needs to be elucidated in further studies. In particular, we examined whether H9N2 virus infection increases PD-L1 expression in endothelial cells in vivo and also mediates immune escape.

\section{Conclusion}

PD-L1 expression is induced in the primary RPMECs infected with the H9N2 virus, and PD-L1 induced by H9N2 virus infection inhibits antiviral interactions between RPMECs and $T$ cells. These results indicate that PD-L1 might be a suitable target for reversing immunosuppression induced by H9N2 virus infection.

\section{Supplementary information}

Supplementary information accompanies this paper at https://doi.org/10. 1186/s12985-020-01341-X.

Additional file 1: Supplementary Figure S1. Map of the PD-L1 overexpression plasmids. According to the current genomic database of the CD274 gene. The targets were designed to include the upstream of the transcript. The PAM sequences of the target sites for CRISPR were TGG. Primers were synthesized, and the oligo dimer was inserted into the vector. DH5a competent cells were used for conversion. Plasmids A and B were mixed at a ratio of 1:1, and RPMECs were transfected with Lipofectamine 3000 reagent according to the instructions. (A) Map of plasmid 1 for MS2-P64-NSF1 expression. (B) Map of plasmid 2 for dCas9-vp64 and gRNA expression.

\section{Abbreviations}

ECs: Endothelial cells; MOI: Multiplicity of infection; RPMECs: Rat pulmonary microvascular endothelial cells; PMECs: Pulmonary microvascular ECs; VEGFr2: Vascular endothelial growth factor receptor 2; AIV: Avian influenza virus; SPF: Specific pathogen-free; HBV: Hepatitis B virus; RSV: Respiratory syncytial virus

\section{Acknowledgments}

This study was supported by the National Key Research and Development Plan (grant number: 2017YFD0501501), the Work Funds for Pig Team Post Experts of Beijing Innovation Team in 2019 (PXM2019014207000024) and the National Natural Science Foundation of China (grant number: 31572558 and 31672597)

\section{Authors' contributions}

QZ participated in the conception and design of the study, carried out the experiments and drafted the manuscript. XM and TZ participated the concept of the study and analyzed the data. HD, GH and TZ modified the manuscript. NS provided H9N2 strain for the study and revised the manuscript. CH participanted in the conception of the study and corrected the manuscript. All the listed authors agreed and approved the final submission.

\section{Funding}

National Key Research and Development Plan (Grant number: 2017YFD0501501), Work Funds for Pig Team Post Experts of Beijing Innovation Team in 2019 (PXM2019014207000024), National Natural Science Foundation of China (Grant number: 31572558 and 31672597).

\section{Availability of data and materials}

All data generated or analyzed during this study are included in this published article.

Ethics approval and consent to participate

Not applicable.

\section{Consent for publication}

Not applicable.

\section{Competing interests}

The authors declare that they have no competing interests.

\section{Author details}

${ }^{1}$ Department of Preventive Veterinary Medicine, College of Veterinary Medicine, China Agricultural University, Beijing 100193, People's Republic of China. ${ }^{2}$ Beijing Key Laboratory of Traditional Chinese Veterinary Medicine, Beijing University of Agriculture, Beijing 102206, People's Republic of China. ${ }^{3}$ National Referece Lab for Poultry Diseases, Animal Sciences Institute, National Agricultural Research Center, Islamabad 45500, Pakistan.

Received: 24 November 2019 Accepted: 10 May 2020

Published online: 06 July 2020

\section{References}

1. Li S, Zhou Y, Zhao Y, Li W, Song W, Miao Z. Avian influenza H9N2 seroprevalence among pig population and pig farm staff in Shandong, China. Virol J. 2015;12:34

2. Peng L, Chen C, Kai-yi H, Feng-xia Z, Yan-li Z, Zong-shuai L, Xing-xiao Z, Shijin J, Zhi-jing X. Molecular characterization of H9N2 influenza virus isolated from mink and its pathogenesis in mink. Vet Microbiol. 2015;176:88-96.

3. Bi Y, Chen Q, Wang Q, Chen J, Jin T, Wong G, Quan C, Liu J, Wu J, Yin R, et al. Genesis, evolution and prevalence of H5N6 avian influenza viruses in China. Cell Host Microbe. 2016:20:810-21.

4. Liu J, Okazaki K, Ozaki H, Sakoda Y, Wu Q, Chen F, Kida H. H9N2 influenza viruses prevalent in poultry in China are phylogenetically distinct from a/quail/Hong Kong/G1/97 presumed to be the donor of the internal protein genes of the H5N1 Hong Kong/97 virus. Avian Pathol. 2003:32:551-60

5. Li C, Yu K, Tian G, Yu D, Liu L, Jing B, Ping J, Chen H. Evolution of H9N2 influenza viruses from domestic poultry in mainland China. Virology. 2005; 340:70-83.

6. Rebelatto MC, Midha A, Mistry A, Sabalos C, Schechter N, Li X, Jin X, Steele KE, Robbins PB, Blake-Haskins JA, Walker J. Development of a programmed cell death ligand-1 immunohistochemical assay validated for analysis of non-small cell lung cancer and head and neck squamous cell carcinoma. Diagn Pathol. 2016:11:95.

7. Francisco LM, Salinas VH, Brown KE, Vanguri VK, Freeman GJ, Kuchroo VK, Sharpe AH. PD-L1 regulates the development, maintenance, and function of induced regulatory T cells. J Exp Med. 2009;206:3015-29.

8. Chikuma S. Basics of PD-1 in self-tolerance, infection, and cancer immunity. Int J Clin Oncol. 2016:21:448-55.

9. Liu Q, Li CS. Programmed cell Death-1/programmed death-ligand 1 pathway: a new target for sepsis. Chin Med J. 2017:130:986-92.

10. Patil NK, Guo Y, Luan L, Sherwood ER. Targeting immune cell checkpoints during sepsis. Int J Mol Sci. 2017;18(11).

11. Ahn J, Bishop JA, Roden R, Allen CT, Best S. The PD-1 and PD-L1 pathway in recurrent respiratory papillomatosis. Laryngoscope. 2018:128:E27-32.

12. Trehanpati $N$, Vyas AK. Immune regulation by $T$ regulatory cells in hepatitis B virus-related inflammation and Cancer. Scand J Immunol. 2017:85:175-81.

13. Akhmetzyanova I, Drabczyk M, Neff CP, Gibbert K, Dietze KK, Werner T, Liu J, Chen L, Lang KS, Palmer BE, et al. Correction: PD-L1 expression on retrovirus-infected cells mediates immune escape from CD8+ T cell killing PLoS Pathog. 2015;11:e1005364.

14. Aurica GT, Vasile L, Michael RE, James AH, Hongwei W, Nathan WB, Patrick M, Mihnea TZ, Tatiana K, Anthony JC, et al. RSV-induced bronchial epithelial cell PD- L1 expression inhibits CD81 T cell nonspecific antiviral activity. J Infect Dis. 2011;203:85-94.

15. Valbuena $G$, Walker DH. The endothelium as a target for infections. Annu Rev Pathol. 2006;1:171-98. 
16. Viemann D, Schmolke $M$, Lueken A, Boergeling Y, Friesenhagen J, Wittkowski H, Ludwig S, Roth J. H5N1 virus activates signaling pathways in human endothelial cells resulting in a specific imbalanced inflammatory response. J Immunol. 2011;186:164-73.

17. Teijaro JR, Walsh KB, Cahalan S, Fremgen DM, Roberts E, Scott F, Martinborough E, Peach R, Oldstone MB, Rosen H. Endothelial cells are central orchestrators of cytokine amplification during influenza virus infection. Cell. 2011;146:980-91.

18. Marelli-Berg FM, Peek E, Lidington EA, Stauss HJ, Lechler RI. Isolation of endothelial cells from murine tissue. J Immunol Methods. 2000;244:205-15.

19. Knieke K, Hoff H, Maszyna F, Kolar P, Schrage A, Hamann A, Debes GF, Brunner-Weinzierl MC. CD152 (CTLA-4) determines CD4 T cell migration in vitro and in vivo. PLoS One. 2009:4:e5702

20. Feng B, Zhang Q, Wang J, Dong H, Mu X, Hu G, Zhang T. IFIT1 expression patterns induced by H9N2 virus and inactivated viral particle in human umbilical vein endothelial cells and bronchus epithelial cells. Mol Cells. 2018:41:271-81

21. Jonges M, Liu WM, van der Vries E, Jacobi R, Pronk I, Boog C, Koopmans M, Meijer A, Soethout E. Influenza virus inactivation for studies of antigenicity and phenotypic neuraminidase inhibitor resistance profiling. J Clin Microbiol. 2010:48:928-40.

22. Stanciu LA, Bellettato CM, Laza-Stanca V, Coyle AJ, Papi A, Johnston SL. Expression of programmed death-1 ligand (PD-L) 1, PD-L2, B7-H3, and inducible costimulator ligand on human respiratory tract epithelial cells and regulation by respiratory syncytial virus and type 1 and 2 cytokines. J Infect Dis. 2006;193:404-12.

23. Thiem A, Hesbacher $S$, Kneitz H, di Primio T, Heppt MV, Hermanns HM, Goebeler M, Meierjohann S, Houben R, Schrama D. IFN-gamma-induced PDL1 expression in melanoma depends on p53 expression. J Exp Clin Cancer Res. 2019:38:397.

24. Mazanet MM, Hughes CC. B7-H1 is expressed by human endothelial cells and suppresses T cell cytokine synthesis. J Immunol. 2002;169: 3581-8.

25. Shanmuganatham K, Feeroz MM, Jones-Engel L, Walker D, Alam S, Hasan M, McKenzie P, Krauss S, Webby RJ, Webster RG. Genesis of avian influenza H9N2 in Bangladesh. Emerg Microbes Infect. 2014;3:e88.

26. Sun Y, Liu J. H9N2 influenza virus in China: a cause of concern. Protein Cell. 2015;6:18-25.

27. Suzuki Y, Ito T, Suzuki T, Holland RJ, Chambers TM, Kiso M, Ishida H, Kawaoka $Y$. Sialic acid species as a determinant of the host range of influenza a viruses. J Virol. 2000;74:11825-31.

28. Nicholls JM, Bourne AJ, Chen H, Guan Y, Peiris JS. Sialic acid receptor detection in the human respiratory tract: evidence for widespread distribution of potential binding sites for human and avian influenza viruses. Respir Res. 2007:8:73

29. Zeng H, Belser JA, Goldsmith CS, Gustin KM, Veguilla V, Katz JM, Tumpey TM. $A(H 7 N 9)$ virus results in early induction of proinflammatory cytokine responses in both human lung epithelial and endothelial cells and shows increased human adaptation compared with avian H5N1 virus. J Virol. 2015;89:4655-67.

30. Humbert M, Hugues S, Dubrot J. Shaping of peripheral T cell responses by lymphatic endothelial cells. Front Immunol. 2016;7:684

31. Zhang WY, Franco DA, Schwartz E, D'Souza K, Karnick S, Reaven PD. HDL inhibits saturated fatty acid mediated augmentation of innate immune responses in endothelial cells by a novel pathway. Atherosclerosis. 2017;259:83-96.

32. Yao L, Korteweg C, Hsueh W, Gu J. Avian influenza receptor expression in $\mathrm{H} 5 \mathrm{~N} 1$-infected and noninfected human tissues. FASEB J. 2008;22:733-40

33. Watanabe T, Kiso M, Fukuyama S, Nakajima N, Imai M, Yamada S, Murakami S, Yamayoshi S, Iwatsuki-Horimoto $K$, Sakoda $Y$, et al. Characterization of H7N9 influenza a viruses isolated from humans. Nature. 2013;501:551-5

34. Hassan KE, Ali A, Shany S, El-Kady MF. Experimental co-infection of infectious bronchitis and low pathogenic avian influenza H9N2 viruses in commercial broiler chickens. Res Vet Sci. 2017:115:356-62.

35. Armstrong SM, Darwish I, Lee WL. Endothelial activation and dysfunction in the pathogenesis of influenza a virus infection. Virulence. 2013:4:537-42.

36. Barnes BJ, Richards J, Mand M, Hanash S, Beretta L, Pitha PM. Global and distinct targets of IRF-5 and IRF-7 during innate response to viral infection. J Biol Chem. 2004:279:45194-207.
37. Dalrymple NA, Mackow ER. Virus interactions with endothelial cell receptors: implications for viral pathogenesis. Curr Opin Virol. 2014;7: 134-40.

38. Telcian AG, Laza-Stanca V, Edwards MR, Harker JA, Wang H, Bartlett NW, Mallia P, Zdrenghea MT, Kebadze T, Coyle AJ, et al. RSV-induced bronchial epithelial cell PD-L1 expression inhibits CD8+ T cell nonspecific antiviral activity. J Infect Dis. 2011;203:85-94.

39. Penaloza-MacMaster P, Provine NM, Blass E, Barouch DH. CD4 T cell depletion substantially augments the rescue potential of PD-L1 blockade for deeply exhausted CD8 T cells. J Immunol. 2015;195:1054-63.

40. Choi J, Enis DR, Koh KP, Shiao SL, Pober JS. T lymphocyte-endothelial cell interactions. Annu Rev Immunol. 2004;22:683-709.

\section{Publisher's Note}

Springer Nature remains neutral with regard to jurisdictional claims in published maps and institutional affiliations.
Ready to submit your research? Choose BMC and benefit from:

- fast, convenient online submission

- thorough peer review by experienced researchers in your field

- rapid publication on acceptance

- support for research data, including large and complex data types

- gold Open Access which fosters wider collaboration and increased citations

- maximum visibility for your research: over $100 \mathrm{M}$ website views per year

At BMC, research is always in progress.

Learn more biomedcentral.com/submissions 